\title{
Comprehensive Rehabilitation Outcome Measurement Scale (CROMS); Development and Preliminary Validation of An Interdisciplinary Measure for Rehabilitation Outcomes
}

Muhammed Rashid ( $\nabla$ rashidkpvld@gmail.com )

JSS College of Physiotherapy https://orcid.org/0000-0002-9332-9280

Sandeep PH

JSS College of Physiotherapy

Akshaiya Kalidas

st. benedict's college of Physiotherapy

Jerin Mathew

University of Otago - Dunedin Campus: University of Otago

kavitha Raja

JSS College of Physiotherapy

\section{Research Article}

Keywords: Functional measurement scale, Rehabilitation outcomes, Rehabilitation, CROMS, Scale validation

Posted Date: November 29th, 2021

DOI: https://doi.org/10.21203/rs.3.rs-1078932/v1

License: (c) (i) This work is licensed under a Creative Commons Attribution 4.0 International License.

Read Full License 


\section{Abstract}

Introduction: Comprehensive and interdisciplinary measurement of rehabilitation outcome is an essential part in the assessment and prognosis of a patient. This requires input from various disciplines working with the patient and the rehabilitation team. Moreover, the evaluation measures should consider the cultural compatibility, cost, and comprehensiveness of the contextual factors of the region and as of the country.

Methods: The new tool was developed through consensus and followed Delphi process incorporating various rehabilitation professionals. The validity, reliability of the tool was tested on 30 patients and their rehabilitation professionals. The tool was also validated in two native languages and back translated considering the semantics. The construct validity was analyzed using interclass correlation co-efficient (ICC), internal consistency was analyzed using Cronbach's alpha.

Results: The final Comprehensive Rehabilitation Outcome Measurement Scale (CROMS) carries 30 items which can be completed by the person with disability and the professional team. The final tool holds an overall ICC of 0.93 with a Cronbach's Alpha of 0.92 for both patient and therapist reported measures.

Conclusion: The 30 item CROMS is a reliable and valid tool that can potentially be used to evaluate functional independence of various patient populations.

\section{Introduction}

Measurement and documentation of health outcomes are critical factors in health care systems and they play a vital role in evidence-based practice $(1,2)$. Appropriate measurement tools are imperative to deliver client-centric rehabilitation care, and accountable and ethical professional practice (3). Progress achieved from any set of interventions must be measured and documented using appropriate tools for determining further course of action and hold prognostic values.

Rehabilitation may be defined as the multi- and interdisciplinary management of a person's functioning and health (4). International Classification of Functioning, Disability, and Health (ICF) provides a coherent view of health from biological, individual, and social perspectives. The interdisciplinary team consists of professionals including physiotherapists (PT), occupational therapists (OT), speech and language pathologists (SLP), clinical psychologists (CP), medical social workers (MSW), registered nurses (RN), medical doctors (MD) working with the patient and family. Each individual has a different yet cooperative role in rehabilitating a patient from the day of admission to community re-entry, achieving the optimum level of functional independence (5). Each discipline in a rehabilitation system is bound to perform individual assessments and formulate appropriate treatment strategies. The patient's progression must be measured and recorded using appropriate outcome measures to help optimise treatment strategies (6). Multiple outcome measures have been developed and used across all rehabilitation disciplines to objectively quantify the patient status and progression (7). The substantial number of validated outcome measurement tools, many of which are discipline specific, may hinder inter disciplinary understanding 
and move away from the patient-first philosophy of rehabilitation. Moreover, they may aid confusion and hinder the consistency of practice even within a single institution $(7,8)$.

There are a variety of functional measurement scales available all over the world. Functional Independence Measure (FIM) (8), Barthel index (BI- 5 and 10 items) (9), Modified Rankin Scale (MRS)(10, $11)$ are some of the more widely used such tools $(12,13)$. These scales often require specific training and have been developed for Western countries considering the specific functional requirements and the overall health care systems in these countries. These tools are limited in utility for conditions in low and middle income countries due to various factors, including the performance of self-care activities, ambulation requirements, and health care system access. The existing tools are notable in the absence of certain domains like hygiene, outdoor ambulation, nursing care requiring the rehabilitation professional to resort to other tools to measure outcomes of rehabilitation. Moreover, generic outcome measures are generally either patient-reported or therapist assessed and rarely encompass both aspects.

Hence the objective of this study was to develop a tool to measure function, relevant for a person with disability in low and middle income countries specifically countries in the global south with two components:

Component 1: A component which is completed by the person with disability.

Component 2: A component which is assessed by a professional team.

\section{Materials And Methods}

To fulfill the objectives, the study was undertaken in two major sections. Section 1 was conducted in four phases using a modified Delphi approach $(14,15)$. The study protocol was reviewed and approved by the institutional review board (JSSCPT_IRB_06/06/2019). Participants or the caregivers included in any of the following phases are eligible to use the scale only if they had a good command over the respective language, did not have any altered mental status, either as previously assessed or as judged by a member or the staff.

\section{Section 1: Development of therapist reported questionnaire}

Section 1 consisted of four phases aimed at developing a patient-reported questionnaire.

\section{Phase I- Item generation}

Participants in the Delphi included all professionals working in an interdisciplinary rehabilitation center. Thus seven physiotherapists, three occupational therapists, a clinical psychologist, two speech and language pathologists, three registered nurses, a medical social worker and a general physician took part in the study. An introductory session was conducted involving all of the professionals wherein the need of the study, objectives and methodology planned were detailed. 
All the rehabilitation professionals recruited for the study were requested to list specific questions regarding functional independence from their area of expertise on the types of patients routinely seen. Components of tools that are commonly used were suggested as a framework so that missing components could be identified and the list of questions could be made comprehensive (16). Moreover, they were told to recapitulate an average working day so that they could go through the various steps and identify areas that are routinely assessed. A series of meetings were conducted every Saturday from 9 AM to 12.30 PM. Each discipline reported the questions documented, and discussions were conducted. This was carried out for three weeks, at which point questions became repetitious. The activity was continued for a further three weeks to ensure data saturation. Questions identified during the past six consensus meetings were listed in order of priority and documented.

\section{Phase II- Item reduction}

A seven-point likert scale was developed as scoring criteria by the team using a consensus approach (17, 18). At successive consensus meetings, items were culled so that only those items, which were feasible and realistic, were taken into consideration. Thirty items were generated ( $A$ to $Z, A A, B B, C C$ and $D D$ ) under seven domains of health. On the next consensus meeting, assessment form and scoring information were generated using an iterative process.

\section{Phase III- Face validation}

Following tool construction, face validity was assessed by six experts (PT, OT, RN, SLP, MSW, and CP) not involved in the item generation phase using a 5 point Likert for each question where 5 was most appropriate and 0 was not at all appropriate. Appropriate revisions were made in consensus meetings between the professionals involved in the first two phases and members in the face validation team, and the tool was finalized. A pilot study of the tool was conducted on volunteers among the patients and caregivers who were in the rehabilitation center (diagnosed as spinal cord injury, stroke, acute idiopathic demyelinating polyneuropathy (AIDP), and head injury) for applicability, clarity, and reliability. An interview was held to see if the questionnaire was exhausting, overwhelming, or frustrating. The responses were transcribed and subjected to a content analysis.

Phase IV - Construct validity, and internal consistency A cohort of 30 patients was assessed using the new tool and relevant items of the existing tool (FIM) to establish construct validity. Some of the items could not be matched with a gold standard to compare with. So these items were omitted for this phase. The internal consistency was analysed using appropriate methods.

\section{Section 2: Development of the patient-reported questionnaire}

This section consisted of three phases aimed at developing a patient-reported questionnaire. This section was performed in the local language of the patients who were available for the process. Two major 
languages of Southern India (Kannada and Malayalam) were utilized in addition to English, since the majority of the patients presented to the study setting had a clear understanding of it.

\section{Phase V-Forward translation of the questionnaire to target languages}

The scale developed in section 1 was translated to the local languages (Kannada and Malayalam) and given to a cohort of 30 patients and their primary caregivers. Fifteen of the patients had completed their rehabilitation and had returned to the community. Participants were requested to mark the question stems for appropriateness and relevance to their lives. Consensus was obtained at a meeting of all participants moderated by the last author (KR).

\section{Phase VI- Back translation to English and finalisation of the tool}

Scoring framework for each stem of the questions was given for relevance and understandability to the cohort. They were asked to use the framework and develop questions to suit each score in an ascending level of independence from 1 to 7 . Finalization was done using a consensus meeting. The final scale, including stems and scoring, was translated back into English using two independent translators, and consensus was obtained through meetings.

\section{Phase VII- Evaluation of concurrence between therapist reported, and patient/caregiver reported questionnaire}

Twenty-five persons with disability were evaluated using the tool by respective professionals. The participants/ primary caregiver self-assessed the person using the patient-reported version of the scale. This phase was performed to assess the concurrence between professional opinion and patient selfreport.

\section{Other properties of the scale}

\section{Time to complete}

The therapist or caregiver who was filling out the questionnaire kept track of the required time to complete the tool. The stages of tool development are depicted in figure 1.

\section{Data analysis}

Phases I, V and VI were analysed descriptively. The item reduction in the phase II was performed using principal component analysis (PCA). In phase IV, the construct validity was analysed using interclass correlation co-efficient (ICC), internal consistency was analysed using Cronbach's alpha using the first set of data obtained in this phase (19). In phase VII, concurrent validity between the therapist reported scale and patient reported scale was analysed using ICC.

\section{Results}


Demographic characteristics of the samples are given in Table 1. 
Table 1

Demographic characteristics of the participants

\begin{tabular}{|c|c|c|}
\hline Variable & Sub group & Number of participants \\
\hline \multicolumn{3}{|l|}{ Age } \\
\hline & $18-30$ & 51 \\
\hline & $30-60$ & 40 \\
\hline & 60 and above & 23 \\
\hline \multicolumn{3}{|l|}{ Sex } \\
\hline & Male & 65 \\
\hline & Female & 49 \\
\hline \multicolumn{3}{|c|}{ Marital status } \\
\hline & Unmarried & 35 \\
\hline & Married & 69 \\
\hline \multicolumn{3}{|c|}{ Diagnosis } \\
\hline & Spinal cord injury & 47 \\
\hline & Cerebro Vascular Accident (CVA) & 28 \\
\hline & Traumatic brain Injury & 17 \\
\hline & Parkinson's disease & 2 \\
\hline & Amputation & 2 \\
\hline & Cerebral Palsy & 9 \\
\hline & Others- Geriatrics, CV and Pulmonary & 9 \\
\hline \multicolumn{3}{|c|}{ Educational status } \\
\hline & Uneducated & 41 \\
\hline & Less than 10th Standard & 25 \\
\hline & 10th -12 th Standard & 31 \\
\hline & Degree & 13 \\
\hline & Postgraduate & 4 \\
\hline \multicolumn{3}{|c|}{ Family system } \\
\hline & Nuclear & 49 \\
\hline & Joint & 65 \\
\hline
\end{tabular}




\begin{tabular}{|c|c|c|}
\hline Variable & Sub group & Number of participants \\
\hline \multicolumn{3}{|c|}{ Area of residence } \\
\hline & Rural & 66 \\
\hline & Urban & 48 \\
\hline \multicolumn{3}{|c|}{ Occupation } \\
\hline & Daily Wage worker & 21 \\
\hline & Farmer & 25 \\
\hline & House wife & 34 \\
\hline & Own employment & 10 \\
\hline & Private sector & 7 \\
\hline & Government sector & 9 \\
\hline & Others & 8 \\
\hline
\end{tabular}

Participants comprised of various sociodemographic factors, and diagnoses were predominantly neurological disability.

\section{Phase I: Item generation}

Three male and three female physiotherapists, two males and one female occupational therapist, one male and two female registered nurses, one male and one female speech therapist, one female general physician, one male medical social worker and one female clinical psychologist were included in the phase one and two. All of them had minimum of five years of clinical experience.

Several questions were repeated by more than one discipline due to the carryover of discipline roles for example between physiotherapists and occupational therapists. Items were culled and the final number of questions were 30 at the end of phase I.

\section{Phase II- Item reduction}

Table 2 shows the results of Principal component analysis. 
Table 2

Components extracted after iteration

\section{Rotated Component Matrix ${ }^{a}$}

Component

$\begin{array}{lllll}\begin{array}{l}\text { Self } \\ \text { care }\end{array} \quad \text { Mobility } & \begin{array}{l}\text { Health } \\ \text { management }\end{array} & \begin{array}{l}\text { Social } \\ \text { cognition }\end{array} & \begin{array}{l}\text { Sphincter } \\ \text { control }\end{array} & \text { Reintegration }\end{array}$

$\begin{array}{ll}\text { Eating } & 0.858 \\ \text { Bathing } & 0.852 \\ \text { Dressing lower } & \mathbf{0 . 8 4 4}\end{array}$

Dressing lower $\quad \mathbf{0 . 8 4 4}$

body

Dressing upper $\quad \mathbf{0 . 7 9 6}$

body

\begin{tabular}{|c|c|c|}
\hline Grooming & 0.690 & 0.315 \\
\hline Outdoor surfaces & & \\
\hline Wheel chair & & \\
\hline Stair & & \\
\hline
\end{tabular}

Bath transfer $\quad 0.504 \quad \mathbf{0 . 7 2 2}$

$\begin{array}{llll}\text { bed_chair_WC_LH } & 0.413 & \mathbf{0 . 7 1 8} & 0.316\end{array}$

Toilet transfer $\quad 0.487 \quad \mathbf{0 . 7 0 9}$

$\begin{array}{llll}\text { Toileting } & 0.397 & \mathbf{0 . 6 7 1} & 0.308\end{array}$

$\begin{array}{lll}\text { bed_chair_WC_HL } & \mathbf{0 . 6 2 9} & 0.608\end{array}$

$\begin{array}{lll}\text { bed_chair_wc_same } & \mathbf{0 . 6 0 7} & 0.516\end{array}$

$\begin{array}{llll}\text { Walk } & 0.485 & \mathbf{0 . 4 9 9} & 0.323\end{array}$

Nutrition and

.896

hydration

Hygiene

.851

Skin integrity

.780

Medication

$\begin{array}{ll}.731 & 0.381\end{array}$

management

Attention to safety $\quad 0.540$

.545

Social interaction

0.843

WC: Wheel chair, LH: Low to high, HL: High to low 


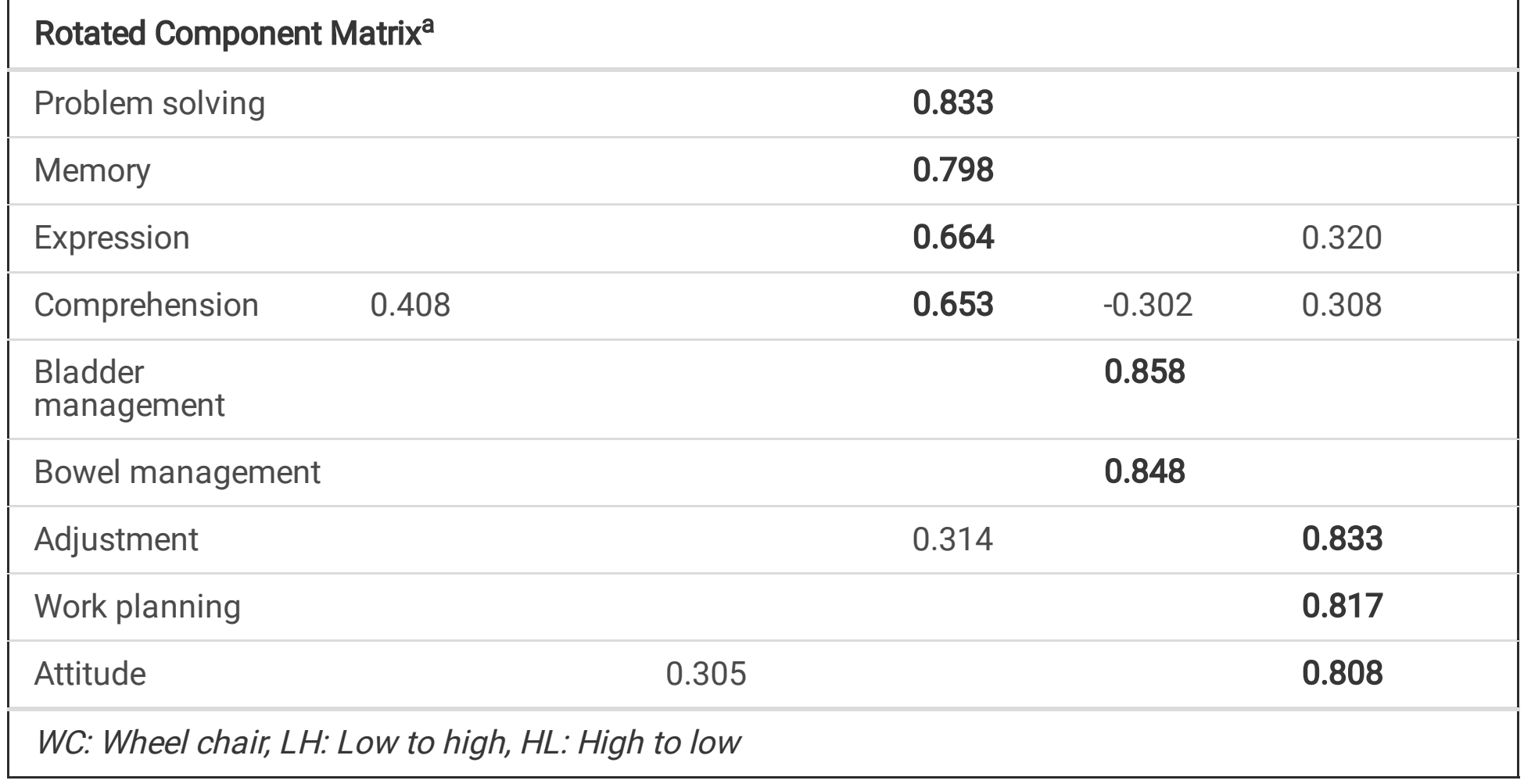

As evident, items loaded on six components. Two domains loaded together on one component named as mobility.

At the end of the phase II, a functional scale with 30 items under various activity and participation was generated. The tool characteristics at the end of phase II is given in Table 3.

Table 3

The tool characteristics at the end of phase II

\begin{tabular}{|lll|}
\hline Domain & Number of questions & Total possible sub score \\
\hline Health management & 5 & 35 \\
\hline Self-care & 5 & 35 \\
\hline Sphincter control & 2 & 14 \\
\hline Mobility & 10 & 70 \\
\hline Commmunication and social cognition & 5 & 35 \\
\hline Reintegration & 3 & 21 \\
\hline Total & 30 & 210 \\
\hline
\end{tabular}

\section{Phase III- Face validation}

The personal and professional characteristics of participants in this phase are given in Table 4. 
Table 4

The personal and professional characteristics of participants involved in phase III

\begin{tabular}{|lllll|}
\hline Participant & Job Role & $\begin{array}{l}\text { Years of } \\
\text { Experience }\end{array}$ & Gender & $\begin{array}{l}\text { Age in } \\
\text { years }\end{array}$ \\
\hline Physiotherapist & Senior Physiotherapist & 10 & Male & 32 \\
$\begin{array}{l}\text { Occupational } \\
\text { Therapist }\end{array}$ & $\begin{array}{l}\text { Senior Occupational } \\
\text { therapist }\end{array}$ & 10 & Female & 34 \\
\hline Speech Therapist & Student therapist & 2 & Female & 23 \\
\hline Staff Nurse & Head Nurse & 7 & Female & 23 \\
\hline Medical Social Worker & Social worker & 3 & Male & 28 \\
\hline Clinical Psychologist & Student volunteer & 2 & Male & 28 \\
\hline
\end{tabular}

All key rehabilitation professional disciplines were included

The results of the face validity are listed in Table 5 .

Table 5

Face validity results

\begin{tabular}{|llll|}
\hline Domain & $\begin{array}{l}\text { Number of questions } \\
\text { changed }\end{array}$ & $\begin{array}{l}\text { Number of questions } \\
\text { deleted }\end{array}$ & $\begin{array}{l}\text { Number of questions } \\
\text { added }\end{array}$ \\
\hline $\begin{array}{l}\text { Health } \\
\text { Management }\end{array}$ & 3 & 2 & 2 \\
\hline Self-care & 2 & 1 & 1 \\
\hline Transfers & 1 & 1 & 1 \\
\hline
\end{tabular}

Minor modification to the scales were made to the scale at this point.

\section{The ease of use and appropriateness of the tool}

A survey was conducted to find out the appropriateness and ease of use of the content in the scale. Eighty-five percentage or more of the participants rated the contents as very appropriate except for the social recognition and integration domains. All the participants reported that $90 \%$ of the items of the scales are very easy.

The result of the pilot study is given in the figure 2

\section{Phase IV- Construct validity, and internal consistency}

Comparison between the FIM and the relevant items of the final therapist reported tool is given in Table 6 
Table 6

Comparison between the FIM and the relevant items of the final therapist reported tool

\begin{tabular}{|llll|}
\hline Domain & Interclass correlation co-efficient & \multicolumn{2}{l|}{$95 \%$ Confidence interval } \\
\cline { 3 - 4 } & & Upper bound & Lower bound \\
\hline Self-care & 0.850 & -0.006 & 0.961 \\
\hline Sphincter control & 0.995 & 0.989 & 0.998 \\
\hline Transfers & 0.966 & 0.922 & 0.988 \\
\hline Locomotor & 0.998 & 0.966 & 0.999 \\
\hline Communication & 0.831 & 0.642 & 0.920 \\
\hline Social cognition & 0.933 & 0.844 & 0.969 \\
\hline
\end{tabular}

Only items that were comparable between the two tools were selected for analysis.

\section{Internal consistency}

The a reliability coefficients $(n=246)$ for the patient reported scale and the therapist reported scale is given in Table 7.

Table 7

Internal consistency of the therapist reported, and patient reported scales

\begin{tabular}{|llll|}
\hline Component & \multicolumn{2}{l}{ Cronbach's Alpha } & Number of items \\
\cline { 2 - 3 } & Therapist reported & Patient reported & \\
\hline 1 & 0.936 & 0.948 & 5 \\
\hline 2 & 0.944 & 0.951 & 9 \\
\hline 3 & 0.911 & 0.933 & 5 \\
\hline 4 & 0.879 & 0.909 & 5 \\
\hline 5 & 0.923 & 0.878 & 3 \\
\hline 6 & 0.961 & 0.958 & 3 \\
\hline Total & & & 30 \\
\hline
\end{tabular}


Table 8

Association between professional reported and patient reported tools

\begin{tabular}{|llll|}
\hline Domain & \multirow{2}{*}{ Interclass correlation co-efficient } & \multicolumn{2}{l|}{$\mathbf{9 5 \% \text { Confidence interval }}$} \\
\cline { 3 - 4 } & & 0.573 & 0.968 \\
\hline Health management bound & Lower bound \\
\hline Self-care & 0.907 & 0.801 & 0.982 \\
\hline Sphincter control & 0.952 & 0.991 & 0.998 \\
\hline Transfers & 0.996 & 0.685 & 0.967 \\
\hline Locomotor & 0.913 & 0.648 & 0.985 \\
\hline Communication & 0.769 & 0.517 & 0.890 \\
\hline Social cognition & 0.638 & 0.213 & 0.835 \\
\hline
\end{tabular}

As evident, the co-efficient were high, indicating good consistency between the two versions.

Phase V: Forward translation of the questionnaire to the target languages

\section{Personal characteristics of the patient/ caregiver who participated in the phase V:}

This phase consisted of patients with general debility, geriatric population, spinal cord injury, Parkinson's disorder, left and right cerebro-vascular disease, Acute idiopathic demyelinating polyneuropathy, traumatic brain injury and 15 primary caregivers of the similar diseased patients.

Eight nine percentage of the participants reported that the contents of each stem in the scale is highly relevant or most appropriate to the patient or caregiver life. Seven percentage of the participants reported that all the contents of the scale was moderately appropriate or relevant and four percentage of the participants reported that all the contents of the scale as moderately relevant or appropriate except social integration, which was reported as slightly appropriate.

\section{Phase Vl: Back translation to English and finalisation of the tool}

Translation was successfully completed with consensus between participants. Minor word choice differences were sorted out through discussion and he translated version was finalized.

\section{Phase VII: Evaluation of concurrence between therapist reported, and patient/caregiver reported questionnaire}

The ICC values of the professional reported scale and self-reported scale is given in table 9. 
With the exception of social cognition, all domains had excellent correlation

\section{Time to complete}

Both therapist and patient assessment required no more than 10 minutes. Patient and caregiver assessments took longer than therapist assessments, however time to complete assessments decreased with time. The average time to complete the scale for the first attempt was 9.4 minutes for patients and 8.7 minutes for caregivers (for therapist). Both participants had a mean period of less than 8 minutes by the third assessment.

\section{Discussion}

Comprehensive Rehabilitation Outcome Measurement Scale (CROMS) was developed as an interdisciplinary venture of PTs, OTs, SLTs, CP, MSW, MD and RNs by compiling specific components to be measured and recorded in a rehabilitation process.

The objective of this study was to develop a tool to measure functioning relevant for a person with disability in India and similar countries. This scale attempted to overcome the difficulties of cultural compatibility, cost and comprehensiveness in currently used scales (20). Some of the additional areas included in CROMS are given in the following paragraphs.

Outdoor uneven surface: In low and middle income countries, a significant part of the work place or the community consist uneven terrain to do their daily functional and vocational work (21). The cumulative experience in clinics of Physiotherapists who have worked with these patients identified the missing components from existing scales. Adding this in the existing domain of locomotion was approved by all the rehab professionals.

Hygiene: There was a missing component on the health management in which hygiene was also noted. The hygiene consisted of clothing, hand washing, perineal bath and bowel and bladder evacuation. This was noted because the care of these areas is also considered one of the individuals' functional tasks. Missing these areas can lead to deterioration of an individual health and leading to deterioration of the physical functioning (or) functional capacity of an individual.

Skin Integrity: The team members recommended considering an individual's skin inspection, changing in position in a timely manner, and identifying the sharp objects or any other surfaces that can breach the skin. Taking this into consideration is important as if there is any damage to the skin, it can lead to physical, psychological and economic burden to the patients and their family (22).

Nutrition and Hydration: The team identified this as it has a direct correlation between the physical functioning of the individual. If a note is not taken on this area, it will definitely lead to deterioration of and individual's functioning. So a healthy diet and hydration was considered to be added in this scale (23-25). 
Medication Management: As majority of the conditions noted by the team requires poly pharmacy, it was also noted that the patient's/ care takers needed to know about the appropriate management of prescribed medications and its effects on functional capacity or condition of an individual $(26,27)$. It was decided that the following areas in medicine management to be considered - remembering medication, timings, guidelines, dosage and accessing of the medications.

Attention to Safety: All the members in phase I, also suggested of adding attention to safety. It is clinically correlated that if the patient or his care takers do not take necessary steps to identify the safety parameters, it can lead to negative effect on the patient. So adding this to the existing tools was considered to be important (28).

Another domain which was identified by the team members is the measurement once the patient is outside the sheltered care, how be the function will respond in the community. It was evident from the previous studies that there is a significant change in the patient's functional status in community due to the mismatch of capacity and actual performance (29). So adding a part of reintegration was considered and the following domains were made - attitude, adjustment and work planning.

a. In the attitude of the individual, his/her attitude towards his disability and attitude of family/ friends were considered. And as the attitude of both will affect the individual's functional capacity, only the attitude towards future was considered. It is proven that the person's attitude or family attitude will prove his reintegration to the community.

b. Due to change in the individual's functional capacity after the trauma to the normal functional system, the person will have to compromise to the existing functional status. This has an effect in his house, place of work, vehicle he uses and other areas of his functioning. It is proven that, the last face of patient's/ family's reaction towards the new disability is acceptance which the patient or family members will consider at early will have a favorable outcome on functional recovery.

c. Work planning: after the loss of normal functional system, the patient and their family members need to adjust for the new skill which he/she has learnt during the rehabilitation. Also it is noted that majority of the patients will not do the same job which was done prior to the injury. And it is evident that planning a work which can be a house hold work or outside the house includes paid and unpaid variant has a significant impact on functional capacity, safety, appropriate skill and time for the individual. So it was decided to add this to the newly developed manual.

The team also noted that there should be an area on readjustment to the community to be assessed. It is noted that an individual needed to learn new skills to get readjusted to the community. The newly learnt skills have to be carried over during individual encounters in the community. If the patient does not acquire these, it may significantly impact his/her functional status.

Phase II

Phase two was of item reduction. In this stage at consensus meeting was done and non-feasible and unrealistic items were removed. 
After this scoring information and assessment form was generated using an iterative process. The scoring scale includes a 7-point ordinal scale with major gradation in behavior from independence to dependence. This was considered because it gives a graded order to designate an individual's function from independence to total dependence. The score zero was given if the activity could not do (or) was not doing prior to the disablement. It is important to consider this as it may change the total score and its interpretation.

As the score has multiple domains, the professionals must complete the recording in 3 working days after admission. It is also to make sure that it can be nullified and get a final score if there is any difference. If the patient has a functional capacity which lies between the scores it was considered to take lower score because it would nullify the false scoring of the patient's functional capacity.

Phase III

In phase III, the face validity of the scale developed was assessed by 6 experts who were not involved in the phase I of this tool construction or item generation. It was assessed by these experts by 5 point Likert for each question for ease of the tool. Experts were unanimous in acceptance of the scale

Our study noted that $80 \%$ of the population in the pilot study were happy with the scale clarity, applicability, and reliability. Also it was added advantage that the type of the patients in the pilot study consisted of persons diagnosed as $\mathrm{SCl}, \mathrm{CVA}, \mathrm{TBI}, \mathrm{HI}$, etc., By that it can be extrapolated that the scale has considered a varied functional changes across varied individuals.

Phase IV

Phase IV was to find the concurrent validity of the newly developed tool. As the scale has taken some of the components (or) has its background of FIM, it was decided to concurrent validate the newly developed tool with FIM.

It was noted that all the FIM domains with the existing scale for ICC were found to be more than 0.8 . It is noted that if ICC is more than $80 \%$, it is considered as good correlation. As FIM is directly having a good ICC for various conditions (TBI, CVA, GBS), it can be extrapolated that the new tool-CROM has a good concurrent validity.

\section{Section 2}

In this section, the patient reported questionnaire was developed in two languages as the objective of the study is to have encompassed both the patient and therapist reported measure.

$70-80 \%$ of the patients reported that questions were at least moderately relevant. From the previous studies, it is evident that if a tool that is generated suggests more than $60 \%$ of content validity, it can be considered as a good tool (30). 


\section{Limitations:}

Some of the limitations noted in the study are, the majority of the clinical condition of the patients in the study were of neurological problems and other areas like orthopedics, cardiorespiratory were not included. Also sampling frame was of one center specific. The participants of neurological category were not matched with condition. Only classical test theory method of tool development was considered for this study.

Future direction

In future the scale should be tested for its psychometric properties for various neurological, orthopedic, cardiac and other health conditions. The responsiveness to change of the tool and Rasch analysis must be evaluated in future.

\section{Conclusion}

From this study, we suggest that CROM is a tool that can potentially be used to evaluate functional independence of a variety of patient populations primarily with neurological dysfunctions both by professionals and patient themselves. Further work is required to validate the tool for specific patient population.

\section{Abbreviations}

- ICF: International Classification of Functioning, Disability, and Health

- PT: Physiotherapist

- OT: Occupational therapist

- SLP: Speech Language Pathologist

- CP: Clinical Psychologist

- MSW: Male Social Worker

- RN: Registered Nurse

- MD: Medical Doctor

- FIM: Functional Independence Measure

- MRS: Modified Ranking Scale

- CROMS: Comprehensive Rehabilitation Outcome Measurement Scale

- SCl: Spinal Cord Injury

- TBI: Traumatic Brain Injury

- HI: Head Injury

\section{Declarations}


Ethics approval and consent to participate

The study protocol was reviewed and approved by the institutional review board (JSSCPT_IRB_06/06/2019). The consent was obtained from the participants before the commencement of the study

\section{Availability of data and materials}

Data and materials used in the study of this manuscript are available from the corresponding author upon request.

\section{Competing interests}

The authors declare that they have no competing interests

\section{Funding}

This was a self-funded study.

\section{Authors' contributions}

MR: Conceptualisation, Data Collection, Data Analysis, Preparation of the draft

SPH: Conceptualisation, Data Collection, Preparation of the draft

AKA: Data Collection

JM: Conceptualisation, Revision of the Manuscript

KR: Development of the tool, Conceptualisation, Revision of the Manuscript

\section{Consent for publication}

Not applicable

\section{Acknowledgments}

Staffs and management of JSS Physical Medicine and Rehabilitation. We would like to acknowledge Mr. Uthamraj, and Mr. Shivu for their contribution during the data collection period.

\section{Authors information}

Not applicable

\section{References}


1. Hawkins RJ. Recommendations for Evaluating and Selecting Appropriately Valued Outcome Measures. Instr Course Lect. 2016;65:587-91.

2. Krousel-Wood MA. Practical considerations in the measurement of outcomes in healthcare. Ochsner J. 1999;1(4):187-94.

3. Pantaleon L. Why measuring outcomes is important in health care. J Vet Intern Med. 2019;33(2):35662.

4. Stucki G, Ewert T, Cieza A. Value and application of the ICF in rehabilitation medicine. Disabil Rehabil. 2002;24(17):932-8.

5. Momsen AM, Rasmussen JO, Nielsen CV, Iversen MD, Lund H. Multidisciplinary team care in rehabilitation: an overview of reviews. J Rehabil Med. 2012;44(11):901-12.

6. Velentgas P, Dreyer NA, Nourjah P, Smith SR, Torchia MM. AHRQ Methods for Effective Health Care. In: . editor. Developing a Protocol for Observational Comparative Effectiveness Research: A User's Guide. Rockville (MD): Agency for Healthcare Research and Quality (US) Copyright @ 2013, Agency for Healthcare Research and Quality.; 2013.

7. L Kinney C. Standardization of Interdisciplinary Clinical Practice and Assessment in Stroke Rehabilitation. International Journal of Physical Medicine \& Rehabilitation. 2013;01(08).

8. Granger CV, Hamilton BB, Linacre JM, Heinemann AW, Wright BD. Performance profiles of the functional independence measure. Am J Phys Med Rehabil. 1993;72(2):84-9.

9. Hsueh IP, Lin JH, Jeng JS, Hsieh CL. Comparison of the psychometric characteristics of the functional independence measure, 5 item Barthel index, and 10 item Barthel index in patients with stroke. J Neurol Neurosurg Psychiatry. 2002;73(2):188-90.

10. Quinn TJ, Dawson J, Walters MR, Lees KR. Reliability of the modified Rankin Scale: a systematic review. Stroke. 2009;40(10):3393-5.

11. Wells JL, Egan M, Byrne K, Jaglal S, Dumbrell AC, Stolee P. Uses of the National Rehabilitation Reporting System: perspectives of geriatric rehabilitation clinicians. Can J Occup Ther. 2009;76(4):294-8.

12. Ravaud JF, Delcey M, Yelnik A. Construct validity of the functional independence measure (FIM): questioning the unidimensionality of the scale and the "value" of FIM scores. Scand J Rehabil Med. 1999;31(1):31-41.

13. Rantz MJ, Popejoy L, Zwygart-Stauffacher M, Wipke-Tevis D, Grando VT. Minimum Data Set and Resident Assessment Instrument. Can using standardized assessment improve clinical practice and outcomes of care? J Gerontol Nurs. 1999;25(6):35-43; quiz 54-5.

14. Stewart D, Gibson-Smith K, MacLure K, Mair A, Alonso A, Codina C, et al. A modified Delphi study to determine the level of consensus across the European Union on the structures, processes and desired outcomes of the management of polypharmacy in older people. PLoS One. 2017;12(11):e0188348.

15. Portney LG, Watkins MP. Foundations of Clinical Research: Applications to Practice: Pearson.; 2013. 
16. Linacre JM, Heinemann AW, Wright BD, Granger CV, Hamilton BB. The structure and stability of the Functional Independence Measure. Arch Phys Med Rehabil. 1994;75(2):127-32.

17. Waggoner J, Carline JD, Durning SJ. Is There a Consensus on Consensus Methodology? Descriptions and Recommendations for Future Consensus Research. Acad Med. 2016;91(5):663-8.

18. Boateng GO, Neilands TB, Frongillo EA, Melgar-Quiñonez HR, Young SL. Best Practices for Developing and Validating Scales for Health, Social, and Behavioral Research: A Primer. Frontiers in Public Health. 2018;6(149).

19. Gupta S, Raja K. eness of Edinburgh Visual Gait Score to Orthopedic Surgical Intervention of the Lower Limbs in Children with Cerebral Palsy. American Journal of Physical Medicine \& Rehabilitation. 2012;91(9).

20. Maher C, Latimer J, Costa L. The relevance of cross-cultural adaptation and clinimetrics for physical therapy instruments. Revista Brasileira de Fisioterapia. 2007;11(4).

21. Hawkins KA, Clark DJ, Balasubramanian CK, Fox EJ. Walking on uneven terrain in healthy adults and the implications for people after stroke. NeuroRehabilitation. 2017;41(4):765-74.

22. Lichterfeld-Kottner A, El Genedy M, Lahmann N, Blume-Peytavi U, Büscher A, Kottner J. Maintaining skin integrity in the aged: A systematic review. Int J Nurs Stud. 2020;103:103509.

23. Wakabayashi H. Rehabilitation nutrition in general and family medicine. J Gen Fam Med. 2017;18(4):153-4.

24. Diekmann R, Wojzischke J. The role of nutrition in geriatric rehabilitation. Curr Opin Clin Nutr Metab Care. 2018;21(1):14-8.

25. Frost JC, Baldwin AJ. 'Food for thought': The importance of nutrition to patient care and the role of the junior doctor. Clin Med (Lond). 2021;21(3):e272-e4.

26. Wagle KC, Skopelja EN, Campbell NL. Caregiver-Based Interventions to Optimize Medication Safety in Vulnerable Elderly Adults: A Systematic Evidence-Based Review. J Am Geriatr Soc. 2018;66(11):212835 .

27. Lau D, Kasper J, Hauser J, Berdes C, Chang C-H, Berman R, et al. Family Caregiver Skills in Medication Management for Hospice Patients: A Qualitative Study to Define a Construct. The journals of gerontology Series B, Psychological sciences and social sciences. 2009;64:799-807.

28. Tyson BT, Pham MT, Brown NT, Mayer TR. Patient safety considerations in the rehabilitation of the individual with cognitive impairment. Phys Med Rehabil Clin N Am. 2012;23(2):315-34.

29. Laukkanen P, Leskinen E, Kauppinen M, Sakari R, Heikkinen E. Health and functional capacity as predictors of community dwelling among older people. Journal of clinical epidemiology. 2000;53:257-65.

30. Halek M, Holle D, Bartholomeyczik S. Development and evaluation of the content validity, practicability and feasibility of the Innovative dementia-oriented Assessment system for challenging behaviour in residents with dementia. BMC Health Serv Res. 2017;17(1):554. 


\section{Figures}

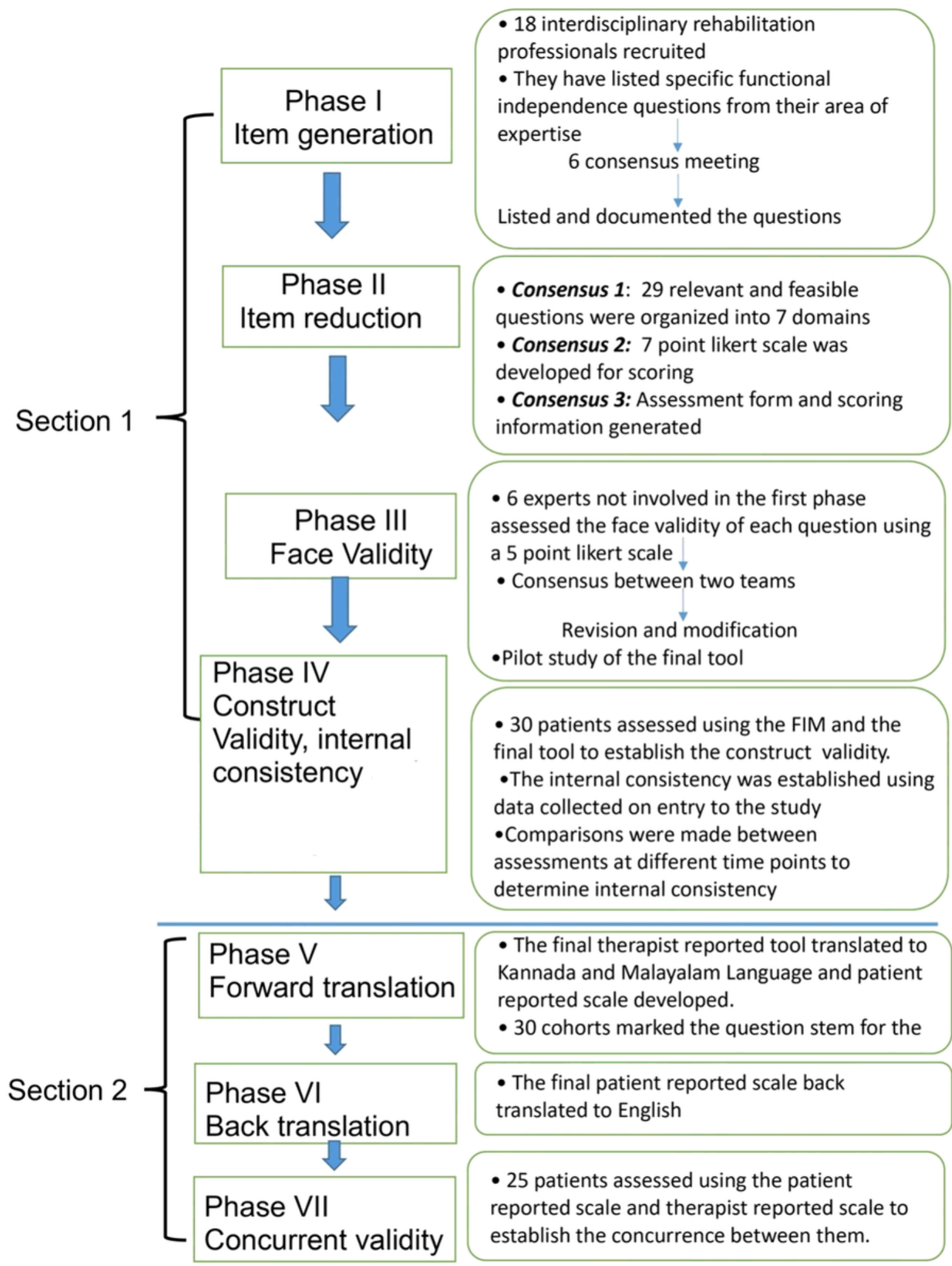

Figure 1

The therapist or caregiver who was filling out the questionnaire kept track of the required time to complete the tool. The stages of tool development are depicted in figure 1. 


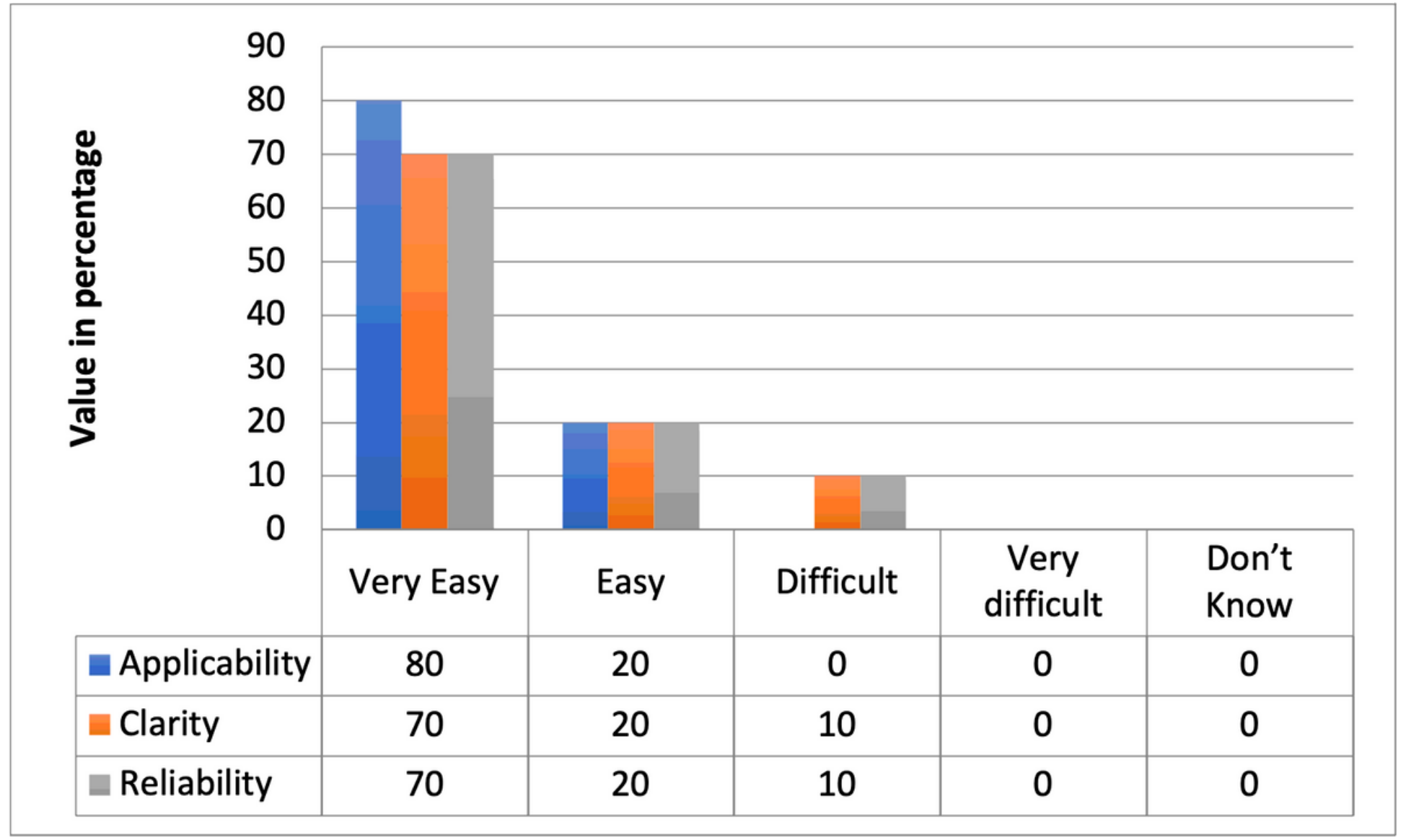

Figure 2

The result of the pilot study is given in the figure 2

\section{Supplementary Files}

This is a list of supplementary files associated with this preprint. Click to download.

- CROMSTherapistreported.docx 